\title{
Maternal Glucocorticoid in Unplanned Premature Labor. Controlled Study on the Effects of Betamethasone Phosphate on the Phospholipids of the Gastric Aspirate and on the Adrenal Cortical Function of the Newborn Infant
}

\author{
KARI TERAMO, ${ }^{(29)}$ MIKKO HALLMAN, AND KARI O. RAIVIO \\ Departments I and II of Obstetrics and Gynecology, and the Children's Hospital, University of Helsinki, \\ 45 Helsinki, Finland
}

\begin{abstract}
Summary
The effects of betamethasone on surfactant composition and neonatal adrenal function were compared with placebo in a doubleblind study, which included 74 patients at risk for premature delivery. The overall incidence of respiratory distress syndrome was low, and no difference was observed between the betamethasone and placebo groups. The phospholipid pattern (lecithin/sphingomyellin ratio, acetone precipitated lecithin, phosphatidylinositol/sphingomyelin ratio, and phosphatidylglycerol/sphingomyelin ratio) from gastric aspirates of newborn infants was similar in the betamethasone and placebo groups, suggesting a similarity in lung surfactant. The responsiveness of the adrenal cortex of the newborn infants, evaluated by a 2 -hr adrenocorticotropic hormone test at the age of $24 \mathrm{hr}$, did not differ between infants whose mothers had received either betamethasone or placebo. The low incidence of respiratory distress syndrome in the betamethasone and placebo groups was ascribed in part to a high incidence of prolonged rupture of fetal membranes. Our results do not exclude the possibility that antenatal maternal administration of betamethasone could prevent respiratory distress syndrome in other defined high-risk infants.
\end{abstract}

\section{Speculation}

Maternal betamethasone administration does not enhance the acceleration of the fetal lung maturation in "fetal stress" due to rupture of fetal membranes, even if the phospholipids of the lung effluent are somewhat immature. Betamethasone phosphate only transiently suppresses fetal adrenal function. Due to the potential long-term side effects, the use of glucocorticoids should be limited to cases in which the risk to develop respiratory distress syndrome is high and spontaneous acceleration of lung maturation is not expected.

Liggins and Howie (13) showed in 1972 that betamethasone administered to the mother prevented respiratory distress syndrome (RDS) in premature infants born before the end of the 32nd pregnancy wk. Block et al. (3) and Morrison et al. (14) have recently partly confirmed the results of Liggins and Howie (13). Block et al. (3) observed a significantly smaller incidence of RDS in infants of mothers treated with betamethasone, when compared to treatment with methylprednisolone or saline. In their study, the interval between the administration of betamethasone and delivery did not affect the incidence of RDS, a finding contrary to the observation of Liggins and Howie. The incidence of RDS was significantly reduced in the study of Block $e t$ al. (3) only when all premature infants were grouped together (including infants up to
37 wk of gestation), whereas Liggins and Howie observed a beneficial effect of betamethasone only in pregnancies lasting 32 wks or less. Morrison et al. (14) injected $500 \mathrm{mg}$ hydrocortisone or placebo IV every $12 \mathrm{hr}$ for $48 \mathrm{hr}$ to mothers at risk for premature delivery. They observed a significant reduction of RDS in patients treated with hydrocortisone (at least two injections) when gestation was less than 32 wk.

Potential side effects of glucocorticoid treatment in the perinatal period have been reported in experimental animals and humans [see review by Taeusch (22)]. There is suggestive evidence that large doses of glucocorticoids given in the perinatal period to rodents decrease the rate of mitosis and myelinization of the brain, with subsequently impaired motor performance $(10,19)$. There is also suggestive evidence that mothers with preeclampsia treated with betamethasone may have increased fetal deaths compared with controls (13). It has been shown in the rabbit that glucocorticoids may compromise placental function (25). Whether the dose of glucocorticoids given antenatally for the prevention of RDS has any effect on the development of the human infant is unknown. As long as this information is lacking, it is important that the indications of treatment, an efficient type of glucocorticoid, and a proper dose and timing of administration be determined in controlled studies.

In the present study, we report the results of a controlled trial of the effect of betamethasone on phospholipid patterns in gastric aspirates from newborn infants and on fetal and maternal adrenal function after maternal betamethasone administration for the prevention of RDS. No difference in the incidence of RDS between the treated and control groups was found, which was due to a low incidence in the control group as well. In addition to safety considerations, our experience may help in defining a group of mothers at risk for premature labor who do not require preventive measures for RDS.

\section{MATERIALS AND METHODS}

The patients were selected from women admitted in premature labor to the Departments I and II of Obstetrics and Gynecology, University of Helsinki. Patients meeting the following criteria were included in the study by one of us (K. T.): (1) gestation between the beginning of the 28th and the end of the 35th wk; (2) cervical dilatation at admission of less than $4 \mathrm{~cm}$; (3) no precipitous progression of labor upon initial observation of up to $12 \mathrm{hr}$; (4) no signs of preeclampsia or diabetes mellitus.

After admission, each patient was started on an infusion of a beta-adrenergic drug (nylidrine or ritodrine) to suppress uterine activity. If the criteria for inclusion in the study were met, the patients received, after informed consent, two IM injections from 
a pair of coded ampules at 24-hr intervals. The pair of ampules contained $3 \mathrm{ml}$ of either betamethasone phosphate solution (12 $\mathrm{mg}$ of betamethasone per dose) or saline, similar in appearance. The betamethasone (Celestone) and placebo ampules were supplied by Schering Corporation, Kenilworth, NJ. The ampules were administered to the patients using the double-blind principle.

The infusion of the beta-adrenergic drug was continued for a minimum of $12 \mathrm{hr}$, during which $50 \mathrm{mg}$ of nylidrine or $100 \mathrm{mg}$ of ritodrine was infused. The infusion was gradually decreased during 24 to $48 \mathrm{hr}$ and followed by IM injections of $5 \mathrm{mg}$ of nylidrine or $10 \mathrm{mg}$ of ritodrine at 5 -hr intervals for two days, after which the drug was administered PO. In cases with premature rupture of fetal membranes, serial white blood cell counts were obtained, and the mother's temperature and fetal heart rate were monitored daily. If signs of infection became apparent, either labor was induced immediately or else a cesarean section was performed, and treatment with antibiotics was started after blood and uterine cervical samples for bacterial cultures had been obtained.

After routine postdelivery care, each infant was transferred to the Children's Hospital for observation. The diagnosis of RDS was based on both clinical criteria (tachypnea, retractions, grunting, and cyanosis) and typical radiological changes in the $\mathrm{X}$-ray pictures of the lung, persisting over $24 \mathrm{hr}$. Therapy was planned on the basis of the clinical picture and blood gas determinations. After completion of the study, the radiograms from each infant were evaluated by Dr. E. Marttinen without knowledge of the clinical condition.

Phospholipid studies were performed in 23 newborn infants. Gastric aspirate was collected within a few min after birth with a PO no. 8 polyethylene suction catheter connected to a mucus trap. The specimen was immediately frozen. Subsequently, lipids were extracted, and phospholipids were analyzed using silicagel plates impregnated with ammonium sulphate, basically as described by Gluck et al. (8). To achieve good separation of individual phospholipids, two-dimensional thin-layer chromatography was used. The first dimension was developed in chloroform/methanol/acetic acid/water $(390 / 150 / 48 / 24 \mathrm{v} / \mathrm{v})$, and the second was developed in tetrahydrofuran/methylal/methanol/ $2 \mathrm{~N}$ ammonium hydroxide $(400 / 196 / 64 / 42 \mathrm{v} / \mathrm{v})$. Between the individual runs, the plates were dried for $10 \mathrm{~min}$ at $60^{\circ} \mathrm{C}$. In addition to the lecithin/ sphingomyelin $(\mathrm{L} / \mathrm{S})$ ratio and the percentage of acetone precipitated lecithin, the phosphatidylinositol/sphingomyelin ratio and phosphatidylglycerol/sphingomyelin ratio were measured. All four parameters characterize pulmonary surfactant and are related to pulmonary maturity $(7,9)$. In two cases, the sample was too small to be analyzed, and one specimen was discarded because of heavy contamination with blood.

To evaluate the effects of maternal betamethasone treatment on fetal and maternal adrenal function, plasma cortisol studies were made in a series on mother-infant pairs. The first maternal sample was taken before the first injection of betamethasone or placebo and the second one at delivery. A sample from the umbilical vein was drawn from the double-clamped cord. At the age of $24 \mathrm{hr}$, an ACTH test was performed. Synthetic adrenocorticotropic hormone (ACTH) was injected IV $\left(0.25 \mathrm{mg} / 1.73 \mathrm{~m}^{2}\right)$ to the newborn infant after a control blood sample, and another sample was drawn after $120 \mathrm{~min}$. Plasma cortisol was determined using a fluorometric method (21).

The statistical differences in the frequencies of perinatal events were evaluated using the $\chi^{2}$ analysis with Yates' correction. The biochemical measurements were evaluated using either the Student's $t$ test or the median test, depending on whether the groups had a normal or nonparametric distribution.

\section{RESULTS}

\section{CLINICAL OBSERVATIONS}

The double-blind betamethasone study was performed during a 17-month period, and a total of 74 patients were included. The mothers ir the betamethasone trial were divided into 3 groups according to the time interval between the drug injection and the delivery (Table 1). Seventeen mothers delivered within less than $24 \mathrm{hr}$ of the first drug injection (group A), 39 mothers received two drug injections and delivered within 7 days of the last injection (group B), and 18 mothers received two injections but delivered more than 7 days after the last injection (group C). There were a total of 6 pairs of twins, 5 in group $A$ and 1 in group B, thus the total number of newborn infants was 80 (Table 1 ).

In group A, four ( 2 betamethasone treated and 2 placebo) of 22 newborn infants (18.5\%) had RDS. In group B, one of the 21 newborn infants in the betamethasone-treated group and one of 19 in the placebo group developed RDS. The total RDS incidence in group B ( 2 of 40 newborn infants or $5 \%$ ) did not, however, differ significantly from the corresponding incidence in group $A$. In group $\mathrm{C}$, none of the newborn infants developed RDS. The study was discontinued because the overall incidence of RDS (6 of 80 newborn infants or $7.5 \%$ ) was too low for any meaningful conclusions concerning the efficacy of prevention, and there were enough cases for phospholipid and cortisol studies. In further clinical comparisons, patients receiving betamethasone were not analyzed separately from those receiving placebo because there was no difference in the RDS incidence.

During the 17-month period of the study, 257 other infants were born alive to 234 mothers before the end of the 35th wk of gestation in this hospital. The mothers of these 257 newborn infants did not receive betamethasone or placebo and thus did not belong to the study groups. Of these 257 infants, $52(20.2 \%)$ developed RDS. This was significantly more than the RDS incidence in the betamethasone study groups $\left(\chi^{2}=5.5 ; P<0.02\right)$. The difference was not explained by a difference in the mean length of gestation [231 days; S.D., 17; in the betamethasone study groups, 230 days, S.D., 16 in the group of infants not belonging to the betamethasone study]. The mean birth weight of the 80 newborn infants belonging to the betamethasone study was 2187 g (S.D., 522), which was significantly more $(P<0.01)$ than the corresponding mean (1991 g; S.D., 476) of the infants not belonging to the betamethasone study. The incidence of cesarean section or antepartum bleeding (placenta previa or premature separation of the placenta) was not different in the study group as compared to the other 234 premature births. However, there was a statistically significant difference $(P<0.001)$ between the groups with respect to the incidence of premature rupture of fetal membranes for more than $24 \mathrm{hr}$ before delivery. The fetal membranes were ruptured for more than $24 \mathrm{hr}$ before delivery in 47 of the 80 newborn infants in the betamethasone study (58.8\%), but only in 39 of the 257 cases (15.2\%) not belonging to the study. The mean one-min Apgar score was 7.56 (S.D., 1.78) in the betamethasone study groups and 6.92 (S.D., 2.51) of the 257 newborn infants not belonging to the betamethasone study.

\section{PHOSPHOLIPID STUDIES}

In four cases of RDS in the betamethasone study, the $\mathrm{L} / \mathrm{S}$ ratio analyzed in gastric aspirate at birth ranged from 0.7 to 1.2 . The corresponding phosphatidylinositol/sphingomyelin ratios were from 0.0 to 0.3 . On the other hand, in 6 of 31 newborn infants with no RDS the L/S ratio was less than two (range, 1.5 to 1.9),

Table 1. Number of mothers and newborn infants in betamethasone and placebo groups

\begin{tabular}{|c|c|c|c|c|c|}
\hline \multirow{2}{*}{ Group } & \multirow{2}{*}{$\begin{array}{c}\text { Time interval between } \\
\text { last drug injection and } \\
\text { delivery (days) }\end{array}$} & \multicolumn{2}{|c|}{ Betamethasone } & \multicolumn{2}{|c|}{ Placebo } \\
\hline & & Mothers & Infants $^{1}$ & Mothers & Infants $^{1}$ \\
\hline $\mathbf{A}$ & $<1$ & 9 & $11(2)$ & 8 & $11(2)$ \\
\hline B & $1-7$ & 21 & $21(1)$ & 18 & $19(1)$ \\
\hline C & $>7$ & 6 & $6(0)$ & 12 & $12(0)$ \\
\hline Total & & 36 & $38(3)$ & 38 & $42(3)$ \\
\hline
\end{tabular}

' Numbers in parentheses, of newborn infants with RDS. 
but the phosphatidylinositol/sphingomyelin ratio in these 6 newborn infants was 0.4 or more (range, 0.4 to 0.7 ). Two of 6 newborn infants with a low $L / S$ ratio but no RDS had attacks of apnea, one had transient tachypnea, and one was hydroptic. Five of the 6 newborn infants with a low L/S ratio but no RDS had a gestational age of less than 32 wk.

Table 2 shows the results of phospholipid analyses in study group B. The L/S ratios, acetone-precipitated lecithins, the phosphatidylinositol/sphingomyelin ratios, and the phosphatidylglycerol/sphingomyelin ratios were not significantly different in the betamethasone and placebo groups.

\section{CORTISOL STUDIES}

The maternal plasma cortisol concentration before the first injection of betamethasone or placebo was $49 \mu \mathrm{g} / 100 \mathrm{ml}$ (S.D. 15; $n=19$ ). There was no difference between the mothers receiving either form of treatment. The rest of the data are summarized in Table 3, arranged in relation to the interval between the first injection and delivery, and to the treatment given.

Table 2. Phospholipids of gastric aspirates of newborn infants at birth ${ }^{1}$

\begin{tabular}{|c|c|c|c|c|c|}
\hline \multirow[b]{3}{*}{$\cdot$} & \multicolumn{4}{|c|}{ No RDS } & \multirow{3}{*}{ RDS } \\
\hline & \multicolumn{2}{|c|}{ Betamethasone } & \multicolumn{2}{|c|}{ Placebo } & \\
\hline & $\begin{array}{l}\text { Me- } \\
\text { dian }\end{array}$ & Range & $\begin{array}{l}\text { Me- } \\
\text { dian }\end{array}$ & Range & \\
\hline Lecithin/sphingomyelin & 2.8 & $1.5-5.0$ & 2.8 & $1.5-9.7$ & $\begin{array}{l}0.8 \\
0.9\end{array}$ \\
\hline $\begin{array}{l}\text { Acetone precipitated leci- } \\
\text { thin (\% of total lecithin) }\end{array}$ & 53 & $39-65$ & 58 & $30-70$ & $\begin{array}{l}43 \\
50\end{array}$ \\
\hline $\begin{array}{l}\text { Phosphatidylinositol/ } \\
\text { sphingomyelin }\end{array}$ & 0.8 & $0.4-2.8$ & 0.7 & $0.4-2.3$ & $\begin{array}{l}0.1 \\
0.2\end{array}$ \\
\hline $\begin{array}{l}\text { Phosphatidylglycerol/ } \\
\text { sphingomyelin }\end{array}$ & 0.0 & $0.0-0.9$ & 0.0 & $0.0-3.2$ & $\begin{array}{l}0.0 \\
0.0\end{array}$ \\
\hline
\end{tabular}

Number of infants

9

12

$2^{2}$

${ }^{1}$ The mothers received either betamethasone or placebo one to seven days prior to delivery (group B).

${ }_{2}^{2}$ One infant belonged to the betamethasone group, and the other belonged to the placebo group.
Because of the number of categories, the number of patients in each category was relatively small and the variation in the cortisol values was considerable. Nevertheless, maternal levels increased between entry to the trial and delivery in the placebo group, but decreased in the betamethasone group; the difference between the two groups was significant when delivery occurred less than $48 \mathrm{hr}$ after the first injection $(P<0.05$; Table 3$)$. The suppression of endogenous cortisol secretion was transient because it was no longer demonstrable in mothers delivered more than $48 \mathrm{hr}$ after the first injection.

The differences in the umbilical vein cortisol values between the placebo and betamethasone cases were analogous to the maternal values, i.e., significantly lower levels in the glucocorticoid-treated cases up to $48 \mathrm{hr}$ after the first injection than in the placebo cases. Regardless of the treatment or the entry-delivery interval, a significant correlation was established between the maternal and umbilical venous plasma cortisol values $(r=0.74$; $n=22$ ).

Examination of the plasma cortisol values of the infants at 24 hr of age showed that betamethasone-induced suppression was no longer demonstrable. Even though the increment in cortisol concentration after ACTH was somewhat lower in the glucocorticoidtreated infants than in the controls, such differences were not statistically significant (Table 3).

\section{DISCUSSION}

It is obvious that in the present study betamethasone was given to patients whose infants had a low risk of developing RDS. Because of potential hazards to the fetus or to the newborn infant involved in antenatal maternal administration of glucocorticoids (22), the use of these drugs should be limited to cases with a substantial risk of RDS. Perinatal asphyxia (4), antepartum bleeding (6), and cesarean section (24) increase the RDS risk in premature deliveries.

Although one large retrospective study (11) failed to show a protective effect of prolonged rupture of fetal membranes on RDS in premature infants, such an effect has been observed in the majority of similar studies $(23,26)$. Our own data are in agreement with the findings that a prolonged time period from the rupture of fetal membranes to the delivery decreases the risk of RDS. We suggest that parturients with premature rupture of fetal membranes should not receive glucocorticoids for prevention of RDS, and this view is further supported by the potential risk of intrauterine infection of these cases.

It has been shown that premature rupture of fetal membranes is associated with increased levels of fetal blood glucocorticoids $(2,15)$ and with an accelerated increase in the $\mathrm{L} / \mathrm{S}$ ratio (18).

Table 3. Plasma cortisol concentrations in the mother and the newborn infant

\begin{tabular}{|c|c|c|c|c|c|c|c|c|c|}
\hline \multirow{3}{*}{$\begin{array}{l}\text { First drug injection-de- } \\
\text { livery interval (hr) }\end{array}$} & \multirow{3}{*}{ Treatment } & \multicolumn{4}{|c|}{ At delivery } & \multicolumn{4}{|c|}{ Newborn infant at $24 \mathrm{hr}$ of age } \\
\hline & & \multicolumn{2}{|r|}{ Maternal vein } & \multicolumn{2}{|c|}{ Umbilical vein } & \multicolumn{2}{|r|}{ Control } & \multicolumn{2}{|c|}{$\begin{array}{c}2 \mathrm{hr} \text { after adrenocortico- } \\
\text { tropic hormone }\end{array}$} \\
\hline & & $\boldsymbol{n}$ & $\begin{array}{c}\text { Cortisol }(\mu \mathrm{g} / 100 \\
\mathrm{ml})\end{array}$ & $n$ & $\begin{array}{c}\text { Cortisol }(\mu \mathrm{g} / 100 \\
\mathrm{ml})\end{array}$ & $n$ & $\begin{array}{c}\text { Cortisol }(\mu \mathrm{g} / 100 \\
\mathrm{ml})\end{array}$ & $n$ & $\begin{array}{c}\text { Cortisol increment } \\
(\mu \mathrm{g} / 100 \mathrm{ml})\end{array}$ \\
\hline \multirow[t]{2}{*}{$<24$} & Placebo & 4 & $86 \pm 32^{1}$ & 3 & $31 \pm 10$ & 4 & $21 \pm 8$ & 4 & $30 \pm 16$ \\
\hline & Betamethasone & 4 & $33 \pm 10^{2}$ & 4 & $10 \pm 2^{3}$ & 2 & $30 \pm 14$ & 2 & $20 \pm 11$ \\
\hline \multirow[t]{2}{*}{$24-48$} & Placebo & 4 & $82 \pm 28$ & 4 & $36 \pm 12$ & 5 & $20 \pm 7$ & 5 & $50 \pm 31$ \\
\hline & Betamethasone & 6 & $36 \pm 27^{2}$ & 4 & $18 \pm 8^{2}$ & 5 & $20 \pm 7$ & 5 & $28 \pm 34$ \\
\hline \multirow[t]{2}{*}{$>48$} & Placebo & 6 & $64 \pm 32$ & 4 & $34 \pm 8$ & 6 & $24 \pm 12$ & 6 & $66 \pm 39$ \\
\hline & Betamethasone & 6 & $80 \pm 37$ & 5 & $36 \pm 18$ & 5 & $37 \pm 13$ & 5 & $50 \pm 42$ \\
\hline
\end{tabular}

\footnotetext{
${ }^{1}$ Mean \pm S.D

${ }^{2} P<0.05$.

${ }^{3} P<0.01$.
} 
According to Spellacy et al. (20) and Caspi et al. (5), dexamethasone treatment increased the $\mathrm{L} / \mathrm{S}$ ratio of the amniotic fluid, whereas Liggins and Howie (13) reported that the L/S ratio was uneffected by betamethasone administration. In the present study, the phospholipids of the gastric aspirate at birth were similar in the betamethasone and placebo groups, suggesting a similarity in lung surfactant. This serves as additional evidence that the glucocorticoid was unable to accelerate lung maturation in this group with a low incidence of RDS. The $\mathrm{L} / \mathrm{S}$ ratios and the phosphatidylinositol/sphingomyelin ratios were consistently lower in infants developing RDS than in "healthy" infants.

According to Liggins and Howie (13), a critical aspect in the success of glucocorticoid prophylaxis is a suitable interval between the administration of the drug and delivery. The hospital admission-delivery time was less than $24 \mathrm{hr}$ in $50 \%$ of the RDS cases in the present study. Another $30 \%$ in this group delivered before the end of the second day after admission to the hospital. This shows another limitation of the usefulness of the glucocorticoid treatment for RDS prevention and underlines the importance of the prevention and postponement of the unplanned premature labor.

Glucocorticoids possibly have a deleterious effect on placental function (or the fetus itself?) in cases with a pre-existing placental insufficiency (13). Block et al. (3) reported 3 intrapartum fetal deaths in 49 cases treated with be:? methasone. In their control group, there was one fetal death $\because 44$ cases. Because of the possible acute hazards of glucocorticoids on the fetus of preeclamptic women and because fetuses of pre-eclamptic women seem to have an accelerated rate of lung maturation (7), parturients with pre-eclampsia should obviously not be treated with glucocorticoids for the prevention of RDS.

Our findings concerning the increase in maternal plasma cortisol during labor and delivery and the decrease caused by betamethasone treatment confirm the results of previous studies $(1,16)$. In a clinical trial similar to ours, Ballard et al. (1) found that suppression of endogenous cortisol secretion was offset by the amount of betamethasone in fetal blood, with a total glucocorticoid activity in the high range at delivery, when expressed as cortisol equivalents.

To evaluate whether the maternal administration of betamethasone had a prolonged suppressive effect on endogenous cortisol secretion, we performed a 2-hr ACTH test in a group of newborn infants. This test has been well standardized for clinical use (12). Our data show that the responsiveness of the adrenal cortex at 24 $\mathrm{hr}$ of age is not impaired, even if the mother has received twice 12 $\mathrm{mg}$ of betamethasone during $24 \mathrm{hr}$ before delivery. This is in agreement with the results obtained by Ohrlander et al. (17), who tested the response to ACTH in newborn infants at varying times after delivery. Our findings indicate that the maternal betamethasone treatment is not hazardous to the newborn infant with respect to the adrenal function in the immediate postnatal period.

The results of our study do not exclude the possibility that antenatal maternal administration of betamethasone could prevent RDS in infants born, e.g., before the end of the 32nd gestational wk. This was the original observation by Liggins and Howie (13). However, the questions about the safety and efficacy of glucocorticoid prophylaxis are still open. We feel that the indications and risks of this treatment should be more clearly defined by controlled studies before its widespread application is justified.

\section{REFERENCES AND NOTES}

1. Ballard, P. I., Granberg, P., and Ballard, R. A.: Glucocorticoid levels in maternal and cord serum after prenatal betamethasone therapy to prevent respiratory distress syndrome. J. Clin. Invest., 56: 1548 (1975).

2. Bauer, C. R., Stern, L., and Colle, E.: Prolonged rupture of membranes associated with a decreased incidence of respiratory distress syndrome. Pediatrics, 53: 7 (1974).

3. Block, M. F., Kling, O. R., and Crosby, W. M.: Antenatal glucocorticoid therapy for the prevention of respiratory distress syndrome in the premature infant. Obstet. Gynecol., 50: 186 (1977).

4. Bruns, P. D., Cooper, W. E., and Drose, V. E.: Maternal-fetal oxygen and acidbase studies and their relationship to hyaline membrane disease in the newborn infant. Am. J. Obstet. Gynecol., 82: 1078 (1961).

5. Caspi, E., Schreyer, P., Weinraub, Z., Bukovsky, I., and Tamir, I.: Changes in amniotic fluid lecithin-sphingomyelin ratio following maternal dexamethason administration. Am. J. Obstet. Gynecol., 122: 327 (1975).

6. Cohen, M. M., Weintraub, D. H., and Lilienfield, A. M.: The relationship of pulmonary hyaline membrane to certain factors in pregnancy and delivery. Pediatrics, 26: 42 (1960).

7. Gluck, L., and Kulovich, M. V.: Lecithin/sphingomyelin ratios in amniotic fluid in normal and abnormal pregnancy. Am. J. Obstet. Gynecol., 115: 539 (1973).

8. Gluck, L., Kulovich, M. V., and Borer, R. C.: Estimates of fetal maturity. Clin. Perinatol., 1: 125 (1974).

9. Hallman, M., Kulovich, M. V., Kirkpatrick, E., Sugarman, R. G., and Gluck, L.: Phosphatidylinositol and phosphatidylglycerol in amniotic fluid: Indices of lung maturity. Am. J. Obstet. Gynecol., 125: 613 (1976).

10. Howard, E.: Reductions in size and total DNA of cerebellum in adult mice after corticosterone treatment in infancy. Exp. Neurol., 22: 191 (1968).

11. Jones, M. D., Burd, L. I., Bowes, W. A., Battaglia, F. C., and Lubchenco, L. O.. Failure of association of premature rupture of the membranes with respiratory distress syndrome. N. Engl. J. Med., 292: 1253 (1975).

12. Leisti, S., and Perheentupa, J.: Two-hour adrenocorticotropic hormone test: accuracy in the evaluation of the hypothalamic-pituitary-adrenocortical axis. Pediatr. Res., 12: 272 (1978).

13. Liggins, G. C., and Howie, R. N.: A controlled trial of antepartum glucocorticoid treatment for prevention of the respiratory distress syndrome in premature infants. Pediatrics, 50: 515 (1972).

14. Morrison, J. C., Whybrew, W. D., Bucovaz, E. T., and Schneider, J. M.: Injection of corticosteroids into mother to prevent neonatal respiratory distress syndrome. Am. J. Obstet. Gynecol., 131: 358 (1978).

15. Murphy, B. E. P.: Cortisol and cortisone levels in the cord blood at delivery of infants with and without the respiratory distress syndrome. Am. J. Obstet. Gynecol., 119: 1112 (1974).

16. Nwosu, U. C., Wallach, E. E., Feldman, J. D., and Bongiovanni, A. M.: Parturition-induced changes in maternal plasma cortisol levels. Obstet. Gynecol., 46: 263 (1975).

17. Ohrlander, S., Gennser, G., Nilsson, K. O., and Eneroth, P.: ACTH test to neonates after administration of corticosteroids during gestation. Obstet. Gynecol., 49: 691 (1977).

18. Richardson, C. J., Pomerance, J. J., Cunningham, M. D., and Gluck, L.: Acceleration of fetal lung maturation following prolonged rupture of the membranes. Am. J. Obstet. Gynecol., 118: 1115 (1974).

19. Shapiro, S.: Some physiological, biochemical, and behavioral consequences of neonatal hormone administration: cortisol and thyroxine. Gen. Comp. Endocrinol., 10: 214 (1968).

20. Spellacy, W. N., Buhi, W. C., Riggall, F. C., and Holsinger, K. L.: Human amniotic fluid lecithin/sphingomyelin ratio changes with estrogen or glucocorticoid treatment. Am. J. Obstet. Gynecol., 115: 216 (1973).

21. Spencer-Peet, J., Daly, J. R., and Smith, V.: A simple method for improving the specificity of the fluorometric determination of adrenal corticosteroids in human plasma. J. Endocrinol., 31 : 235 (1965).

22. Taeusch, H.W.: Glucocorticoid prophylaxis for respiratory distress syndrome: $A$ review of potential toxicity. J. Pediatr., 87: 617 (1975).

23. Thibeault, D. W., and Emmanouilides, G. C.: Prolonged rupture of fetal membranes and decreased frequency of respiratory distress syndrome and patent ductus arteriosus in preterm infants. Am. J. Obstet. Gynecol., 129: 43 (1977).

24. Usher, R. H., Allen, A. C., and McLean, F. H.: Risk of respiratory distress syndrome related to gestational age, route of delivery, and maternal diabetes. Am. J. Obstet. Gynecol., 111: 826 (1971).

25. Wellman, K. F., and Volk, B. W.: Fine structural changes in the rabbit placenta induced by cortisone. Arch. Pathol., 94: 147 (1972).

26. Worthington, D., Maloney, A. H. A., and Smith, B. T.: Fetal lung maturity. I. Mode of onset of premature labor. Influence of premature rupture of the membranes. Obstet. Gynecol., 49: 275 (1977).

27. The authors thank Dr. E. Martinen for his cooperation in evaluating the radiograms of the newborn infants.

28. Requests for reprints should be addressed to: Kari Teramo, M.D., Department of Obstetrics andGynecology, University of Helsinki, 00290 Helsinki, Finland.

29. This research was supported by the Foundation for Pediatric Research in Finland.

30. Received for publication December 19, 1978.

31. Accepted for publication July 5, 1979. 